\title{
Dielectric Properties and Characterisation of Titanium Dioxide Obtained by Different Chemistry Methods
}

\author{
Aleksandra Wypych, ${ }^{1}$ Izabela Bobowska, ${ }^{1}$ Milena Tracz, ${ }^{2}$ Agnieszka Opasinska, \\ Slawomir Kadlubowski, ${ }^{3}$ Alicja Krzywania-Kaliszewska, ${ }^{4}$ Jaroslaw Grobelny, ${ }^{2}$ \\ and Piotr Wojciechowski ${ }^{1}$ \\ ${ }^{1}$ Department of Molecular Physics, Faculty of Chemistry, Lodz University of Technology, Żeromskiego 116, 90-924 Lodz, Poland \\ ${ }^{2}$ Department of Materials Technology and Chemistry, Faculty of Chemistry, University of Lodz, Pomorska 163, 90-236 Lodz, Poland \\ ${ }^{3}$ Institute of Applied Radiation Chemistry, Lodz University of Technology, Wróblewskiego 15, 93-590 Lodz, Poland \\ ${ }^{4}$ Institute of Polymer and Dye Technology, Lodz University of Technology, Stefanowskiego 12/16, 90-924 Lodz, Poland \\ Correspondence should be addressed to Aleksandra Wypych; alwypych@p.lodz.pl
}

Received 10 January 2014; Accepted 11 February 2014; Published 19 March 2014

Academic Editor: Jean-Francois Hochepied

Copyright (C) 2014 Aleksandra Wypych et al. This is an open access article distributed under the Creative Commons Attribution License, which permits unrestricted use, distribution, and reproduction in any medium, provided the original work is properly cited.

\begin{abstract}
We made comparison of titanium dioxide powders obtained from three syntheses including sol-gel and precipitation methods as well as using layered (tetramethyl)ammonium titanate as a source of $\mathrm{TiO}_{2}$. The obtained precursors were subjected to step annealing at elevated temperatures to transform into rutile form. The transformation was determined by Raman measurements in each case. The resulting products were characterised using Raman spectroscopy and dynamic light scattering. The main goal of the studies performed was to compare the temperature of the transformation in three titania precursors obtained by different methods of soft chemistry routes and to evaluate dielectric properties of rutile products by means of broadband dielectric spectroscopy. Different factors affecting the electrical properties of calcinated products were discussed. It was found that sol-gel synthesis provided rutile form after annealing at $850^{\circ} \mathrm{C}$ with the smallest particles size about $20 \mathrm{~nm}$, the highest value of dielectric permittivity equal to 63.7 , and loss tangent equal to 0.051 at $\mathrm{MHz}$ frequencies. The other powders transformed to rutile at higher temperature, that is, $900^{\circ} \mathrm{C}$, exhibit lower value of dielectric permittivity and had a higher value of particles size. The correlation between the anatase-rutile transformation temperature and the size of annealed particles was proposed.
\end{abstract}

\section{Introduction}

In the last decade the production and use of titanium dioxide $\left(\mathrm{TiO}_{2}\right)$ have increased steadily due to its common availability, chemical stability, nontoxicity, optical-electronic properties, low cost, and high photocatalytic properties. $\mathrm{TiO}_{2}$ crystallizes in several crystallographic polymorph phases. Among them the most popular are anatase and rutile. Anatase phase is mostly formed at low temperatures, while rutile is thermodynamically stable at higher temperatures [1]. The nanosized anatase has attracted considerable attention as a photocatalyst, being used for the chemical treatment of organic pollutants [2] or as a component of organic light emitting diodes facilitating charge transport and electrical injection [3]. Titanium dioxide in rutile form exhibits high dielectric constant and can be considered as a component in low temperature cofired ceramics (LTCC) [4] or as a filler in hybrid (i.e., organic-inorganic) composites $[5,6]$. The dielectric properties of a composite material depend on the dielectric constants of the components, that is, polymer matrix and inorganic filler. Therefore, the nanoparticles of rutile $\mathrm{TiO}_{2}$ with nanometer size, low dispersity, and elevated values of dielectric permittivity are strongly required for application in modern electronics [7].

Nanostructured $\mathrm{TiO}_{2}$ can be produced by laser chemical vapor deposition [8], physical vapor deposition [9], and large variety of chemical methods [10]. Wet chemistry methods are particularly valuable for the synthesis of oxide nanoparticles, 
because they are simple and economical and can be easily controlled giving highly pure and homogeneous products with desired size and morphology. Within wet chemistry methods one can find thermohydrolysis, sol-gel, and precipitation as well as hydrothermal route that requires autoclave [11]. The thermohydrolysis of $\mathrm{TiCl}_{4}$ in water leads usually to a mixture of different $\mathrm{TiO}_{2}$ phases (anatase, rutile, and brookite) depending on the reagent ratio, $\mathrm{pH}$, temperature, and time $[12,13]$, whereas sol-gel and precipitation methods provide to titania precursor or semicrystalline $\mathrm{TiO}_{2}$ in anatase phase [14-16]. A transformation from anatase to rutile phase requires processing at elevated temperatures [17]. During thermal treatment several undesirable effects occur that are adverse for nanopowder engineering, that is: sintering connected with a grains growth, aggregation and disorders in desired morphology. We believe that control of initial nanoscopic morphology of anatase particles and mild thermal treatment will allow for the preparation of rutile particles with nanometer size and low dispersity.

Recently Marinel et al. [18] reported dielectric properties of $\mathrm{TiO}_{2}$ ceramics conventionally and microwave sintered at the temperatures above $1000-1300^{\circ} \mathrm{C}$. The dielectric constant values were high and equal about 100 for measurement performed at RT and at the frequency of $100 \mathrm{~Hz}$. These high values were achieved by preparation of high density ceramic sinters; however the morphology of the sinters precludes their use as fine-grained fillers in hybrid dielectrics.

The objective of this study was to investigate the effect of thermal treatment on the structure, morphology, and dielectric properties of rutile nanoparticles obtained via soft chemistry routes and mild thermal treatment. The synthesised powders can be considered for potential application as a filler in high- $\kappa$ nanocomposites.

\section{Materials and Methods}

2.1. Materials. All reagents were commercially available and used without further purification. Titanium (IV) isopropoxide $\left(97 \%\right.$, $\mathrm{Ti}\left(\mathrm{CH}\left(\mathrm{CH}_{3}\right)_{2}\right)$, TIP); titanium (IV) chloride $\left(\geq 99.0 \%, \mathrm{TiCl}_{4}\right)$; and tetramethylammonium hydroxide solution ( 25 wt.\% in $\left.\mathrm{H}_{2} \mathrm{O},\left(\mathrm{CH}_{3}\right)_{4} \mathrm{~N}(\mathrm{OH}), \mathrm{TMAOH}\right)$ were purchased from Sigma-Aldrich. Glacial acetic acid (puriss., $\mathrm{CH}_{3} \mathrm{COOH}$ ); ammonia solution (25 wt.\% in $\mathrm{H}_{2} \mathrm{O}, \mathrm{NH}_{3 \mathrm{aq}}$ ); sulfuric acid (puriss., $\mathrm{H}_{2} \mathrm{SO}_{4}$ ); and 2-propanol (puriss., $\left.\left(\mathrm{CH}_{3}\right)_{2} \mathrm{CHOH}\right)$ were purchased from Avantor Performance Materials Poland.

\subsection{Synthesis Protocols}

2.2.1. Synthesis (1). The titanium dioxide $\mathrm{TiO}_{2}-(1)$ was synthesised via sol-gel method at low temperature according to Behnajady et al. [14]. First, $2.95 \mathrm{~mL}(9.96 \mathrm{mmol})$ of TIP was mixed with $0.57 \mathrm{~mL}(9.96 \mathrm{mmol})$ of glacial acetic acid. Next, $36.0 \mathrm{~mL}$ ( $2 \mathrm{~mol}$ ) of MilliQ water was added dropwise under vigorous stirring and maintaining the temperature of the mixture around $0^{\circ} \mathrm{C}$. After $1 \mathrm{~h}$ the homogenous sol was obtained that was stored in the darkness by 12 hours for nucleation process. Thereafter, the sol was annealed at the temperature of $70^{\circ} \mathrm{C}$ for gelation process. The white gel was dried at $100^{\circ} \mathrm{C}$ for $12 \mathrm{~h}$ and subjected to step calcination.

2.2.2. Synthesis (2). The $\mathrm{TiO}_{2}$-(2) was synthesised according to the method described by Ohya et al. [15]. First, $3 \mathrm{~mL}$ $(10.13 \mathrm{mmol})$ of TIP was added to $2.36 \mathrm{~mL}(3.95 \mathrm{mmol})$ $15 \mathrm{wt} . \%$ water solution of TMAOH. The 12 hours of vigorous stirring of mixture under nitrogen atmosphere yielded finally two-phase transparent sol. A white precipitate was obtained by adding an excess of 2-propanol to the sol. The precipitate was separated by centrifugation, washed with 2-propanol, and finally dried at $70^{\circ} \mathrm{C}$ under vacuum.

2.2.3. Synthesis (3). The $\mathrm{TiO}_{2}$-(3) was synthesised according to protocols outlined by Li and Zeng [16]. A $1 \mathrm{~mL}(9.12 \mathrm{mmol})$ of $\mathrm{TiCl}_{4}$ was slowly added to the $19.4 \mathrm{~mL}$ of diluted $10 \mathrm{wt} . \%$ sulfuric acid, maintaining the reaction temperature at $0^{\circ} \mathrm{C}$. After 0.5 hours of vigorous stirring a gray solution was obtained. The mixture became transparent after annealing it at $60^{\circ} \mathrm{C}$. The temperature was raised slowly to $80^{\circ} \mathrm{C}$. Thereafter, the $25 \mathrm{wt} . \%$ aqueous ammonia solution was added dropwise to $\mathrm{pH}$ 7. The obtained white suspension was cooled down to room temperature and stored for 12 hours. Finally, the white sediment was centrifuged and dried at room temperature under vacuum.

The dried powders obtained from specified $(1 \div 3)$ syntheses were subjected to stepwise annealing procedures at $300,500,600,750,850$, and $900^{\circ} \mathrm{C}$ under normal atmospheric conditions for two hours at each temperature.

2.3. Characterisation Methods. Raman spectra were acquired with use of JobinYvon T64000 triple-gratings spectrometer equipped with the Olympus BX40 confocal microscope. Arion laser line $514.5 \mathrm{~nm}$ was used for samples excitation.

SEM images were obtained using a Hitachi S3000 scanning electron microscope (accelerating voltage of $25000 \mathrm{~V}$ ).

The dielectric properties of $\mathrm{TiO}_{2}$ in the form of pellets were investigated using a Novocontrol GmbH Concept 40 broadband dielectric spectrometer (BDS) equipped with Quatro Cryosystem operating in the frequency range of $10^{-1}$ $10^{6} \mathrm{~Hz}$ and in the temperature range of $-140^{\circ} \mathrm{C}$ to $200^{\circ} \mathrm{C}$ (in steps of $\left.10^{\circ} \mathrm{C}\right)$. The obtained complex dielectric function $\left(\varepsilon^{*}\right)$ was measured by:

$$
\varepsilon^{*}=\varepsilon^{\prime}-i \varepsilon^{\prime \prime},
$$

where $\varepsilon^{\prime}$ and $\varepsilon^{\prime \prime}$ are the real part and the imaginary or loss part, respectively. The dielectric dissipation factor, that is, loss tangent $(\tan (\delta))$, was defined according to the relation: $\tan (\delta)=\varepsilon^{\prime \prime} / \varepsilon^{\prime}$.

To form pellets of the synthesised titanium dioxides, the powders obtained after synthesis and subsequent annealing were pressed under a load of $44.5 \mathrm{kgmm}^{-2}$ for 10 minutes. The received pellets were very brittle; thus they were additionally sintered for $2 \mathrm{~h}$ under normal atmospheric conditions at $850^{\circ} \mathrm{C}$ or $900^{\circ} \mathrm{C}$, depending on previous annealing procedure, in order to improve their mechanical properties. To provide good contact between the sample and external electrodes 
during electrical investigations, $150 \mathrm{~nm}$ thick gold electrodes were deposited on both sites of each pellet. The densities of the samples were evaluated based on the external dimensions and mass of the pellets. The relative density of prepared pellets was estimated through comparison with crystallographic density of $\mathrm{TiO}_{2}$ (for anatase $3.89 \mathrm{~g} / \mathrm{cm}^{3}$, ICDD-PDF2: code number 00-021-1272; for rutile $4.25 \mathrm{~g} / \mathrm{cm}^{3}$, ICDDPDF-2 code number 00-021-1276). To exclude the influence of humidity each pellet was additionally dried at $90^{\circ} \mathrm{C}$ for one hour under reduced pressure directly before dielectric measurement.

Particle sizes, obtained in a different step of calcination, were estimated from dynamic light scattering (DLS) technique. For measurements Malvern Zetasizer Nano ZS instrument equipped with $\mathrm{He}-\mathrm{Ne}$ laser operating at $633 \mathrm{~nm}$ was used. To perform DLS measurements $0.00125 \mathrm{M}$ aqueous solutions of titania obtained from described synthesis and annealed at different temperature were prepared. The solutions were sonicated in an ultrasonic bath for one hour and additionally 3 minutes prior to measurement in order to ensure proper dispersion of the particles. DLS data were collected in automatic duration mode for solution placed in quartz cuvettes with square aperture using the light being detected at an angle of $173^{\circ}$ and at temperature stabilised to a value of $25^{\circ} \mathrm{C}$. The correlation function was processed using the density and refraction index parameters corresponding to $\mathrm{TiO}_{2}$, in anatase and rutile form, and $\mathrm{H}_{2} \mathrm{O}$.

\section{Results and Discussion}

3.1. Raman Spectroscopy Studies. The as-synthesised samples were subjected to a subsequent annealing at the temperatures ranging from 500 to $900^{\circ} \mathrm{C}$. The Raman spectroscopy was used for structural identification of annealed samples. The Raman spectra of titania polymorphs are enough distinctive and they are very useful for identification of various $\mathrm{TiO}_{2}$ phases. The anatase has six Ramanactive modes in the vibrational spectrum centered around $144 \mathrm{~cm}^{-1}\left(\mathrm{E}_{\mathrm{g}}\right), \quad 197 \mathrm{~cm}^{-1}\left(\mathrm{E}_{\mathrm{g}}\right), \quad 399 \mathrm{~cm}^{-1}\left(\mathrm{~B}_{1 \mathrm{~g}}\right)$, $513 \mathrm{~cm}^{-1}\left(\mathrm{~A}_{1 \mathrm{~g}}\right), \quad 519 \mathrm{~cm}^{-1}\left(\mathrm{~B}_{1 \mathrm{~g}}\right)$, and $639 \mathrm{~cm}^{-1}\left(\mathrm{E}_{\mathrm{g}}\right)$ [10]. The rutile $\mathrm{TiO}_{2}$ has four vibrational modes around $145 \mathrm{~cm}^{-1}\left(\mathrm{~B}_{1 \mathrm{~g}}\right), 445 \mathrm{~cm}^{-1}\left(\mathrm{E}_{\mathrm{g}}\right), 610 \mathrm{~cm}^{-1}\left(\mathrm{~A}_{\mathrm{lg}}\right)$, and $240 \mathrm{~cm}^{-1}$ for second-order effect (SOE) [19]. The analysis of Raman spectra of samples annealed at $600^{\circ} \mathrm{C}$ (data not shown) revealed pure anatase phase with high crystallinity for all synthesised $\mathrm{TiO}_{2}-(1), \mathrm{TiO}_{2}-(2)$, and $\mathrm{TiO}_{2}-(3)$ samples. Further annealing leads to a gradual anatase to rutile phase transformation. Figure 1 illustrates Raman spectra of the samples $\mathrm{TiO}_{2}-(1), \mathrm{TiO}_{2}-(2)$, and $\mathrm{TiO}_{2}-(3)$ annealed at $750^{\circ} \mathrm{C}$. Spectra of $\mathrm{TiO}_{2}-(2)$ and $\mathrm{TiO}_{2}-(3)$ show peaks characteristic for anatase, whereas the Raman spectrum of $\mathrm{TiO}_{2}-(1)$ obtained from sol-gel method shows Raman peaks characteristic for both anatase and rutile phases. An increase of the annealing temperature up to $850^{\circ} \mathrm{C}$ brings profound changes in the Raman spectra (Figure 2) of $\mathrm{TiO}_{2}-(1)$ and $\mathrm{TiO}_{2}-(3)$ with a presence of bands typical for rutile phase, whereas the Raman spectrum of $\mathrm{TiO}_{2}-(2)$

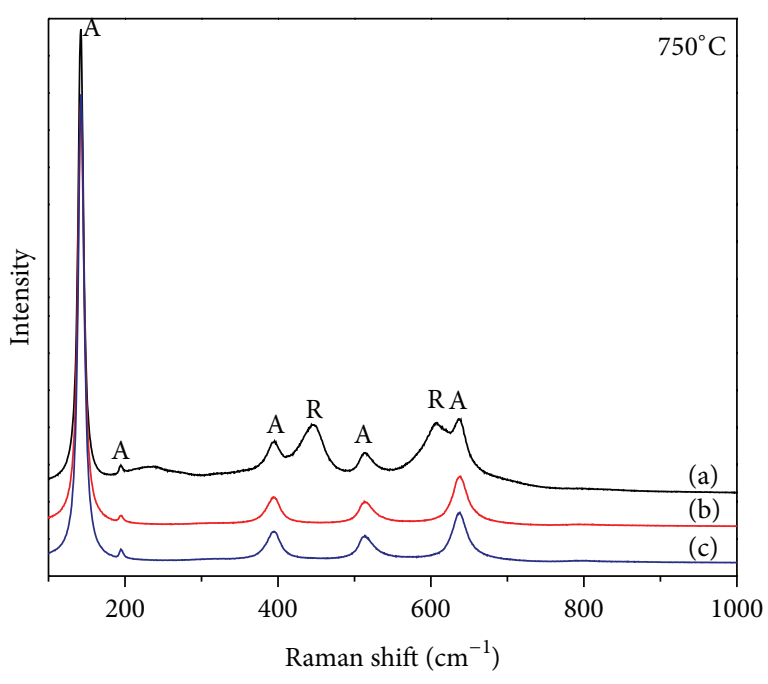

FIGURE 1: Raman spectra of the $\mathrm{TiO}_{2}$ powders annealed at $750^{\circ} \mathrm{C}$ for 2 hours: (a) $\mathrm{TiO}_{2}-$ (1), (b) $\mathrm{TiO}_{2}-(2)$, and (c) $\mathrm{TiO}_{2}-$ (3). Raman modes of anatase and rutile phases are denoted by $\mathrm{A}$ and $\mathrm{R}$, respectively.

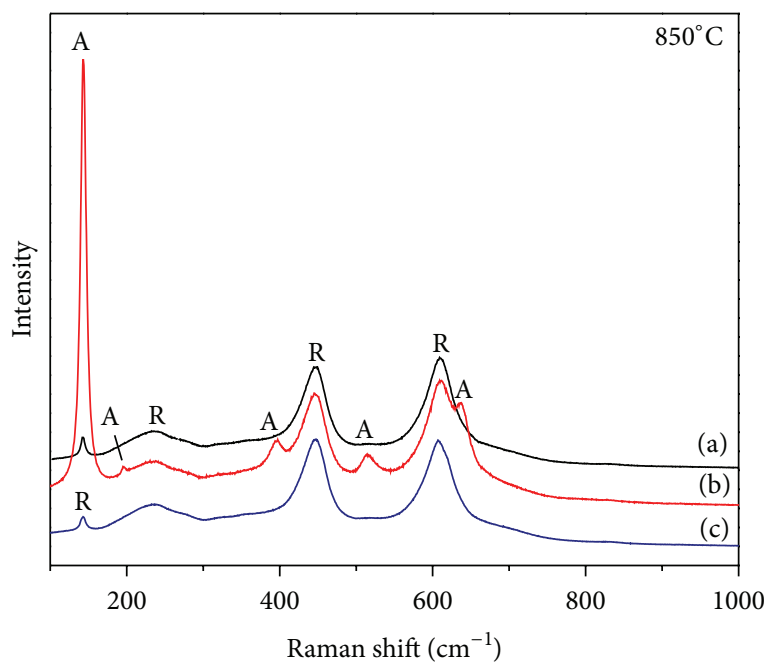

FIGURE 2: Raman spectra of the $\mathrm{TiO}_{2}$ powders annealed at $850^{\circ} \mathrm{C}$ for 2 hours: (a) $\mathrm{TiO}_{2}-(1)$, (b) $\mathrm{TiO}_{2}-(2)$, and (c) $\mathrm{TiO}_{2}-$ (3). Raman modes of anatase and rutile phases are denoted by $\mathrm{A}$ and $\mathrm{R}$, respectively.

exhibits bands indicative of both anatase and rutile phases. Figure 3 illustrates Raman spectra of products obtained after subsequent annealing at $900^{\circ} \mathrm{C}$. The Raman spectra of $\mathrm{TiO}_{2}-(1)$ (Figure 3(a)) and $\mathrm{TiO}_{2}-(3)$ (Figure 3(c)) show bands characteristic for rutile and compared to the Raman spectra of these samples annealed at $850^{\circ} \mathrm{C}$, one can see only slight narrowing of the widest bands. The Raman spectrum of the sample $\mathrm{TiO}_{2}$-(2) still exhibits strong bands characteristic for anatase phase, but the relative intensity of the highest band centered around $144 \mathrm{~cm}^{-1}$ is visibly lower compared to the Raman spectrum shown in Figure 2(b). This change reveals progress in phase transformation from anatase to rutile; however the transformation of sample $\mathrm{TiO}_{2}-(2)$ was not completed at this temperature. 


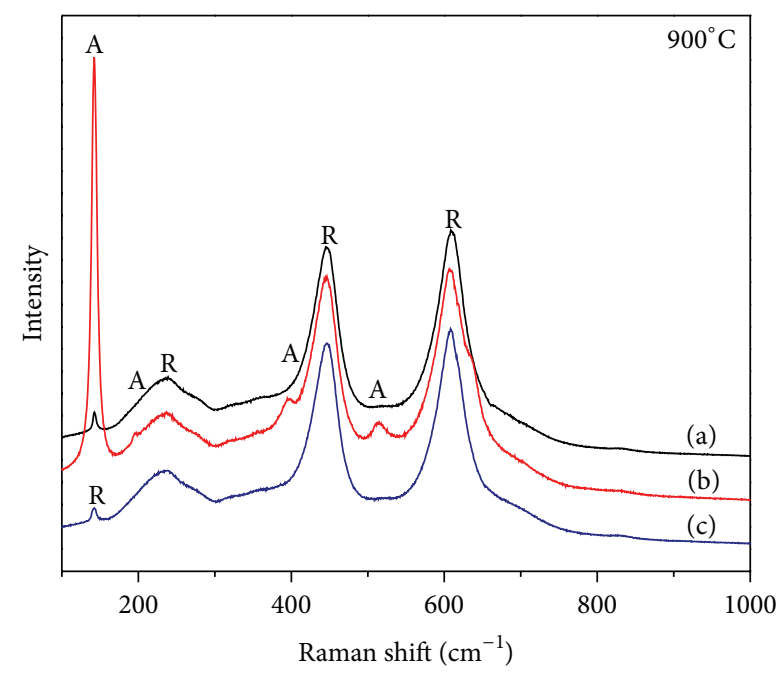

Figure 3: Raman spectra of the $\mathrm{TiO}_{2}$ powders annealed at $900^{\circ} \mathrm{C}$ for 2 hours: (a) $\mathrm{TiO}_{2}-(1)$, (b) $\mathrm{TiO}_{2}-$ (2), and (c) $\mathrm{TiO}_{2}-$ (3). Raman modes of anatase and rutile phases are denoted by $\mathrm{A}$ and $\mathrm{R}$, respectively.

According to literature the temperature of anatase to rutile phase transformation is about $915^{\circ} \mathrm{C}$ [20]. In the present study, we observed a decrease in the transformation temperature which is due to the nanocrystalline structure of synthesised samples. Similar results were obtained in studies performed by Zhang et al. [21]. They observed distinct changes in phase transformation temperatures between samples composed of anatase nanoparticles of different sizes ranging from 7 to $60 \mathrm{~nm}$. According to this the temperature of phase transformation for the initial anatase particles smaller than $10 \mathrm{~nm}$ was lower than $600^{\circ} \mathrm{C}$; the anatase nanoparticles with size in the range $10-60 \mathrm{~nm}$ transformed at the temperatures range between 900 and $1000^{\circ} \mathrm{C}$, whereas particles of a size greater than $60 \mathrm{~nm}$ transformed to rutile at temperature above $1000^{\circ} \mathrm{C}$. The samples $\mathrm{TiO}_{2}-(1)$ and $\mathrm{TiO}_{2}$ (3) exhibit complete anatase to rutile phase transformation achieved at the annealing temperature of $850^{\circ} \mathrm{C}$, whereas for the sample $\mathrm{TiO}_{2}-(2)$ the phase transformation was still incomplete up to the temperature of $900^{\circ} \mathrm{C}$. Moreover, the Raman analysis revealed that the first signs of the phase transformation were observed for the sample $\mathrm{TiO}_{2}-(1)$ in the temperature of $750^{\circ} \mathrm{C}$. According to Zhang et al. [21] and based on the observed temperatures of phase transformation, we can assume that the smallest size of anatase nanoparticles characterises the sample $\mathrm{TiO}_{2}-(1)$ and the biggest particles of anatase are in the sample $\mathrm{TiO}_{2}-(2)$. The Raman spectrum of sample $\mathrm{TiO}_{2}-(2)$ shows bands characteristic for anatase and rutile phases. The anatase content in this partially transformed sample can be evaluated based on the work of Zhang and coworkers [17], where the Raman spectra of anataserutile mixtures with different composition were analysed. The authors presented the linear relationship between the area ratios of the Raman band at $395 \mathrm{~cm}^{-1}$ for anatase phase to the band at $445 \mathrm{~cm}^{-1}$ for rutile phase and the weight ratios of anatase phase to rutile phase. Based on this relation, the estimated anatase content in the sample $\mathrm{TiO}_{2}-(2)$ after annealing at $900^{\circ} \mathrm{C}$ is less than $10 \mathrm{wt} . \%$.

3.2. Dynamic Light Scattering Measurements. Figure 4 shows dynamic light scattering data weighted by numbers (Figure 4(a)) and volume (Figure 4(b)) of $\mathrm{TiO}_{2}$ (rutile) particles obtained from three different syntheses. $\mathrm{TiO}_{2}$ obtained via synthesis (1) was annealed at $850^{\circ} \mathrm{C}$, whereas the precursors obtained from syntheses (2) and (3) had to be annealed at $900^{\circ} \mathrm{C}$ to transform in rutile phase. The number weighted DLS measurement of the product from synthesis (1) exhibits one peak corresponding to a fraction of particles with size in the range of $10 \div 40 \mathrm{~nm}$ that corresponds to the amount of $99 \%$ of all particles in the solution. The volume-weighted representation exhibits three main peaks of decreasing magnitude located at about $20 \mathrm{~nm}, 60 \mathrm{~nm}$, and $230 \mathrm{~nm}$, whereas the fraction of nanoparticles with average size of about $20 \mathrm{~nm}$ constitutes $46 \%$ of the total volume of the dispersed phase. Rutile nanoparticles obtained from syntheses (2) and (3) exhibit unimodal distributions of particle size, both in number and volume representations. The size of nanoparticles coming from synthesis (2) varies in the range $90 \div 260 \mathrm{~nm}$, with a mean value equal to 150. Dispersity value, called in the past a polydispersity index (PDI), defined in ISO13321 Part 8 for this series of nanoparticles is equal to 0.71 . Nanoparticles from synthesis (3) exhibit slightly narrower size distribution than the (2) product with PDI equal to 0.43 . In this case the size is ranging from $90 \mathrm{~nm}$ to $300 \mathrm{~nm}$ with a mean value equal to $160 \mathrm{~nm}$ and $180 \mathrm{~nm}$ as deduced from the representations given at Figures 4(a) and 4(b). From DLS measurements it can be concluded that titania nanoparticles obtained via method (1) possess similar dispersity (PDI $=0,49$ ) compared to series (3). The same conclusion can be drawn through SEM micrographs (see Figure 5) which were performed in order to study the morphology of obtained rutile powders.

3.3. Scanning Electron Microscopy Investigations. Figure 5(a) shows the SEM image of $\mathrm{TiO}_{2}$ powder obtained via synthesis (1) and annealed at the temperature of $850^{\circ} \mathrm{C}$. The average size of particles is about $20 \mathrm{~nm}$ and they are slightly agglomerated. Figures 5(b) and 5(c) show SEM images of $\mathrm{TiO}_{2}$ annealed at the temperature of $900^{\circ} \mathrm{C}$, obtained via syntheses (2) and (3), respectively. Both images reveal large grains. The SEM image of $\mathrm{TiO}_{2}-(2)$ reveals also high dispersity of particles size. The size of the biggest rectangular grains equals $300 \mathrm{~nm}$ and the size of the smallest one is approximately $50 \mathrm{~nm}$. The SEM image of $\mathrm{TiO}_{2}-(3)$ shows much bigger agglomerates than these observed for $\mathrm{TiO}_{2}-(1)$; however, it can be observed that the larger particles are composed of smaller grains. The SEM analysis confirms that the most uniform and the finest morphology of rutile nanoparticles was obtained via sol-gel method, whereas the highest dispersity characterises $\mathrm{TiO}_{2}$ (2) sample. These findings are in agreement with results of DLS investigations.

3.4. Broadband Dielectric Spectroscopy Studies. In order to characterise the dielectric properties of synthesised titania 


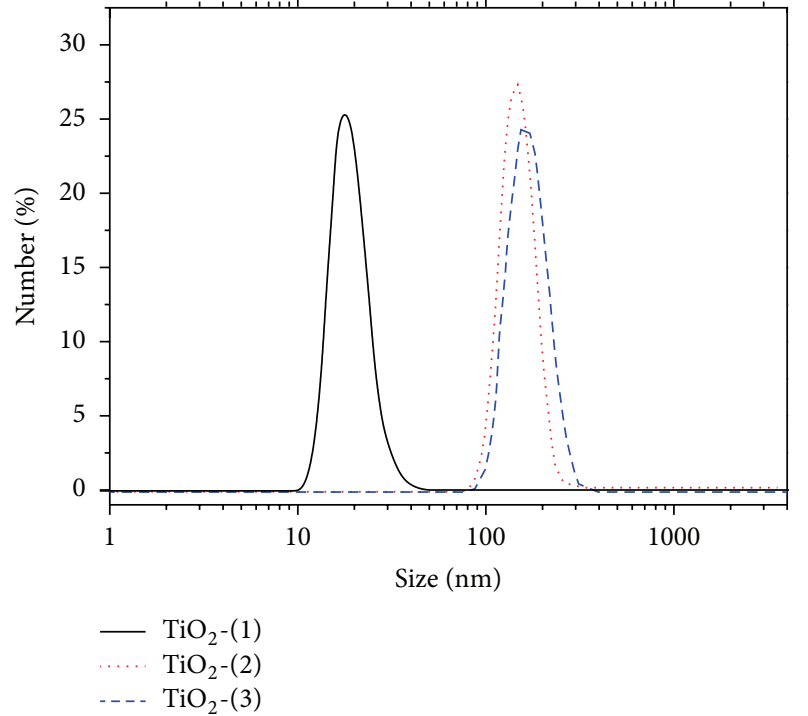

(a)

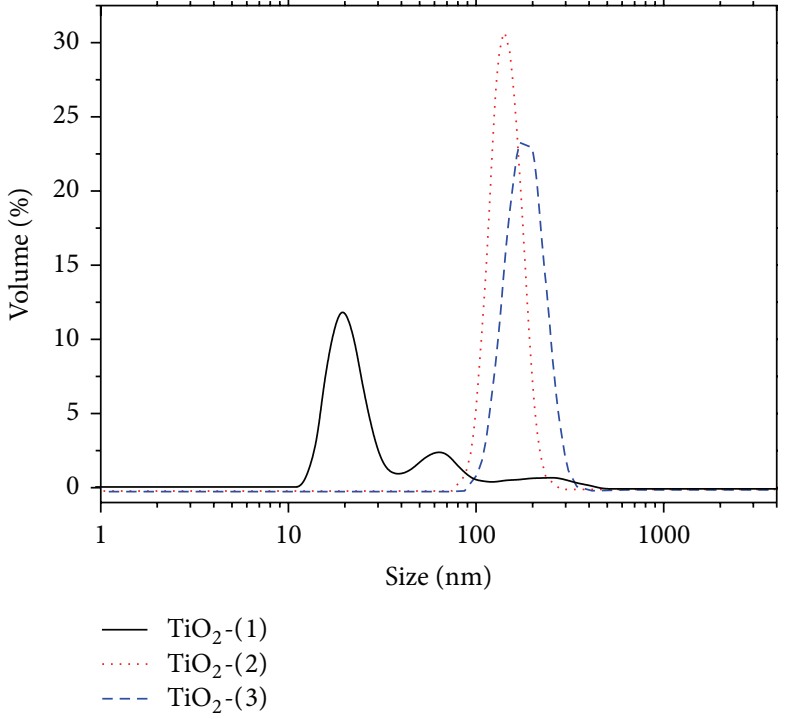

(b)

FIGURE 4: Dynamic light scattering (DLS) measurements of size dispersion of the titania in rutile form obtained from three different syntheses and subjected to annealing at $850^{\circ} \mathrm{C}$ (synthesis (1)) and at $900^{\circ} \mathrm{C}$ (syntheses (2) and (3)). Figures $4(\mathrm{a})$ and 4 (b) represent data weighted by number and volume of particles, respectively.

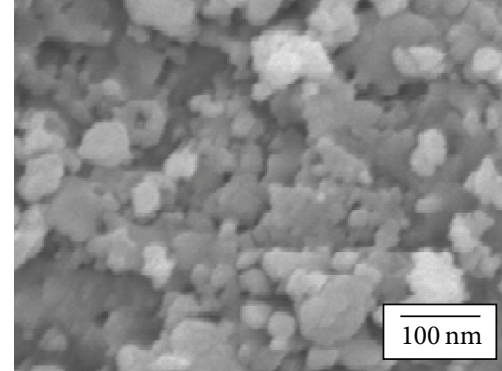

(a)

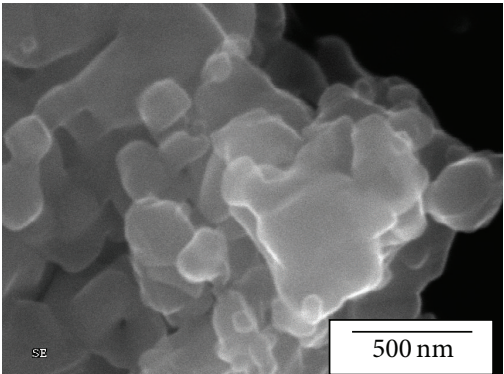

(b)

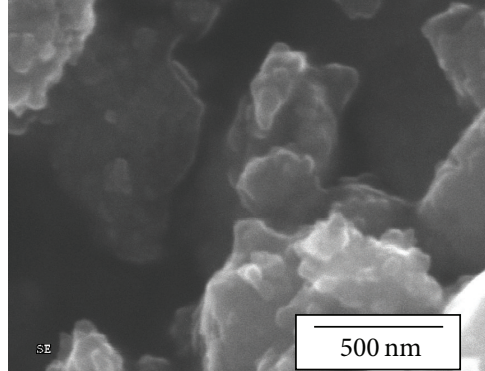

(c)

Figure 5: SEM images of titania samples annealed for two hours: (a) $\mathrm{TiO}_{2}-(1)$ at $850^{\circ} \mathrm{C}$, (b) $\mathrm{TiO}_{2}-(2)$ at $900^{\circ} \mathrm{C}$, and (c) $\mathrm{TiO}_{2}-(3)$ at $900^{\circ} \mathrm{C}$.

we have applied the broadband dielectric spectroscopy that allowed determining the physical properties useful for evaluation of ceramic's applications, such as dielectric permittivity $\left(\varepsilon^{*}\right)$, loss tangent $(\tan (\delta))$, and temperature coefficient of resonant frequency $\left(\tau_{\varepsilon}\right)$. In Figure 6 one can see three dimensional (3D) graphs comprising the temperature-frequency representations of dielectric permittivity (Figure 6(a)) and loss tangent (Figure 6(b)) corresponding to rutile obtained via synthesis (1) after annealing at $850^{\circ} \mathrm{C}$. The loss tangent representation exhibits that in a range of temperature from $-20^{\circ} \mathrm{C}$ to $120^{\circ} \mathrm{C}$ there is a presence of relaxation phenomenon. Despite this, the increase of investigated variables at low frequency and at high temperature was evidenced that is connected with contribution of ionic conductivity in such experimental conditions. Figure 7, being a frequency representation of measured variables in chosen temperatures, shows that dielectric constant decreases with frequency increase. It results from the fact that in ceramic materials the electric response is complex and composed of polarisation contributions from different molecular levels as well as space charge polarisations. The dipolar polarisation decreases when dipole rotation cannot follow electric field changes at high frequencies that results in the decreasing value of dielectric constant [22]. A relaxation phenomenon, pointed by arrow in loss tangent representation in Figure 7(b), can be connected with energy dissipation on the grain boundaries or/and effect of electrode $[23,24]$. These representations are exemplary also for other dielectrically investigated samples; however their loss maxima appear in different range of temperature.

Figure 8 shows frequency dependence of the real part of dielectric constant $\left(\varepsilon^{\prime}\right)$ and loss tangent $(\tan (\delta))$ measured at $20^{\circ} \mathrm{C}$ for three rutile samples obtained from different synthesis and after annealing conducted at $850^{\circ} \mathrm{C}$ for (1) product and at $900^{\circ} \mathrm{C}$ for (2) and (3) materials. It can be observed 


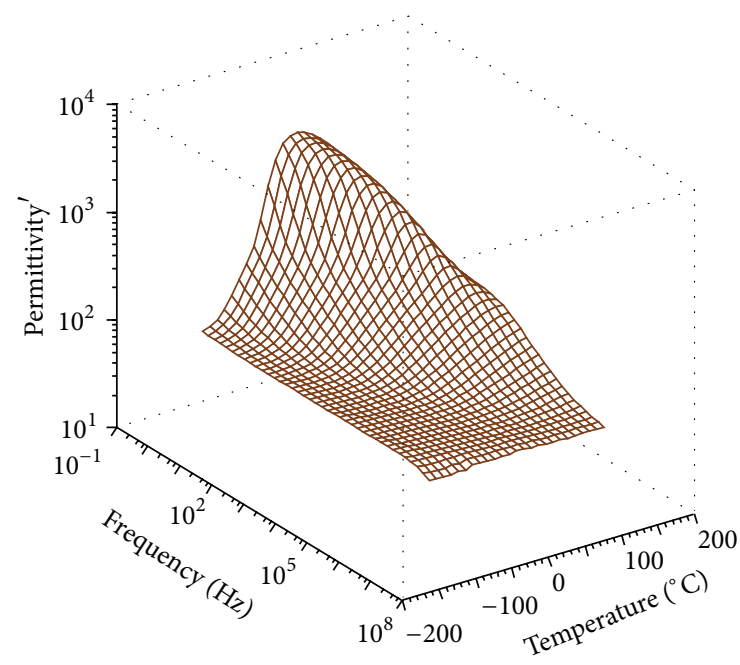

(a)

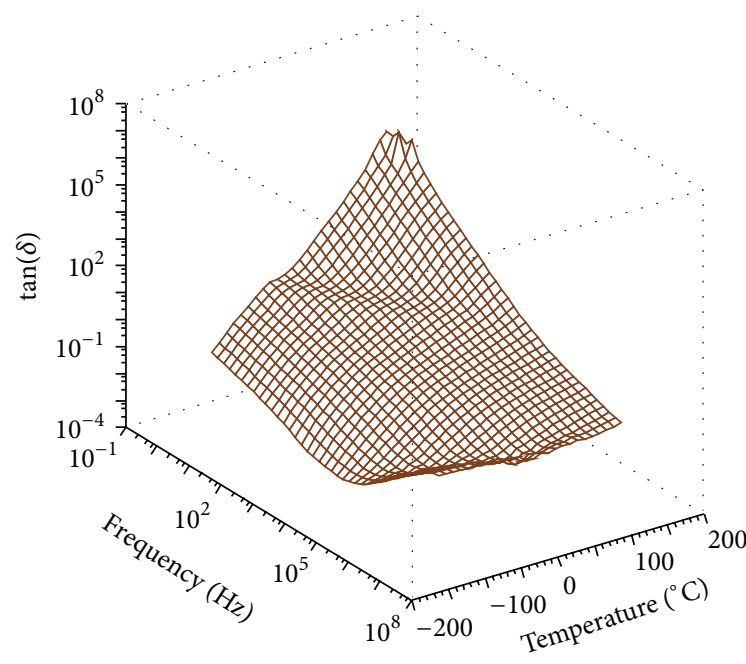

(b)

FIgURE 6: Temperature-frequency representation of (a) a real part of dielectric permittivity and (b) loss tangent measured for $\mathrm{TiO}_{2}-(1)$ annealed for $2 \mathrm{~h}$ at $850^{\circ} \mathrm{C}$.

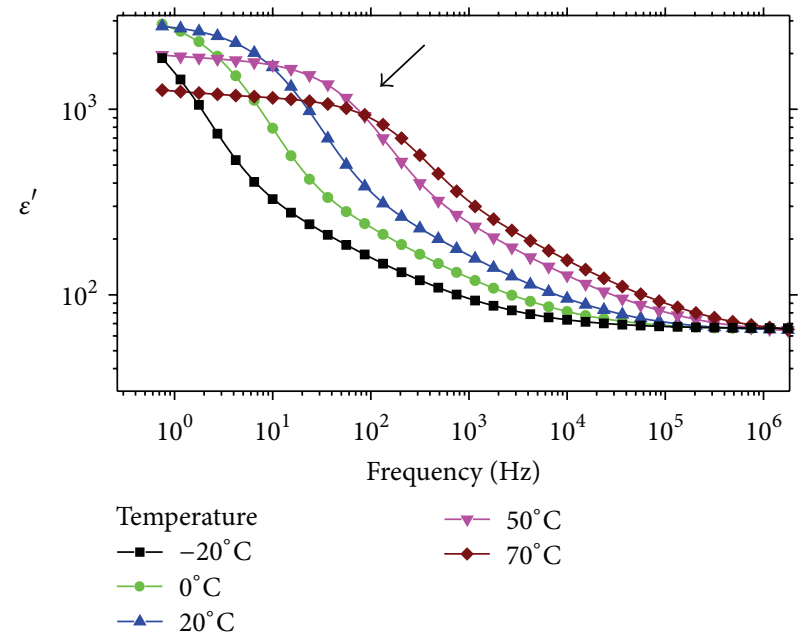

(a)

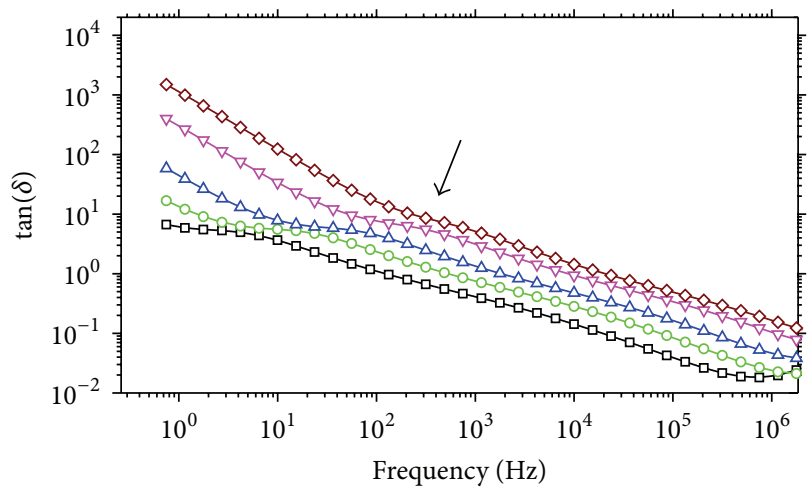

$$
\begin{array}{ll}
\text { Temperature } & -\nabla-50^{\circ} \mathrm{C} \\
-\square--20^{\circ} \mathrm{C} & -\sim 70^{\circ} \mathrm{C} \\
--00^{\circ} \mathrm{C} & \\
-\triangle-20^{\circ} \mathrm{C} &
\end{array}
$$

(b)

FIGURE 7: The frequency dependence of (a) dielectric constant and (b) loss tangent measured at different temperatures for TiO ${ }_{2}-(1)$ annealed for $2 \mathrm{~h}$ at $850^{\circ} \mathrm{C}$.

that rutile sample obtained from synthesis (1) exhibits the highest value of dielectric permittivity equal to 63.7 with dielectric loss of 0.051 as measured at $\mathrm{MHz}$ frequencies. It is worth mentioning that titania in anatase form, obtained from the same synthesis and annealed at $600^{\circ} \mathrm{C}$, exhibits much lower dielectric constant equal to 18.9 and significantly higher loss tangent of 0.130 in the same frequency range (result not presented). Titanium oxides from syntheses (2) and (3) after calcination at $900^{\circ} \mathrm{C}$ possess dielectric constant equal to 17.0 and 43.2, respectively, which is illustrated in Figure 8(a) and the $\tan (\delta)$ equal to 0.055 and $4 \cdot 10^{-4}$ at $1 \mathrm{MHz}$ (see Figure $8(\mathrm{~b}))$. It is worth underlining that $\mathrm{TiO}_{2}-(3)$ exhibits semiflat frequency response of dielectric permittivity value in broad frequency range and the smallest values of loss tangent from all investigated rutile samples. The dissipation factor measured at $20^{\circ} \mathrm{C}$ for $\mathrm{TiO}_{2}-(1)$ and $\mathrm{TiO}_{2}-(2)$ has similar values. Samples $\mathrm{TiO}_{2}-(2)$ and $\mathrm{TiO}_{2}-(3)$ annealed at $900^{\circ} \mathrm{C}$ exhibit smaller values of $\varepsilon^{\prime}$ compared to rutile $\mathrm{TiO}_{2}-(1)$. In the case of $\mathrm{TiO}_{2}-(2)$ this can be explained by uncompleted anatase-rutile transformation gradually going on grains' boundary with formation of intermediate product with coreshell structure. Zhang et al. found that anatase-rutile transformation is strongly dependent on particle size and going from the surface of particle to its centre or reverse depending on particles' size [21]. Taking into account DLS and SEM results it can be concluded that rutile particles obtained from synthesis 


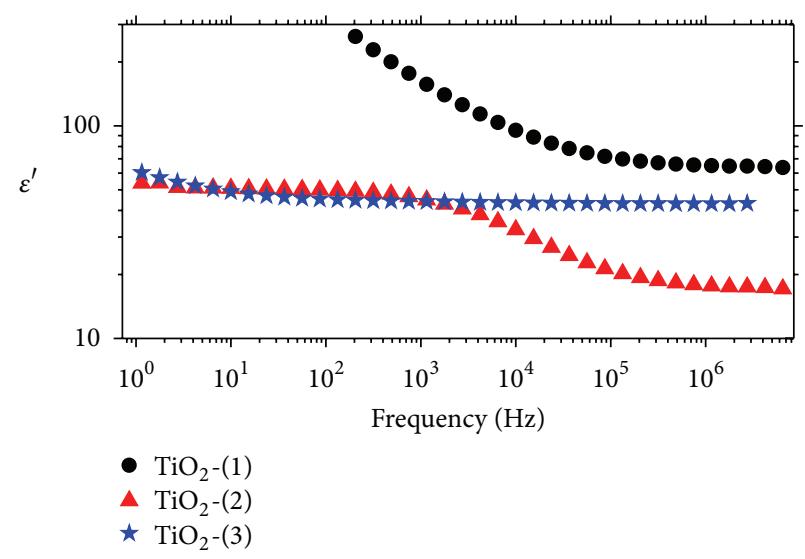

(a)

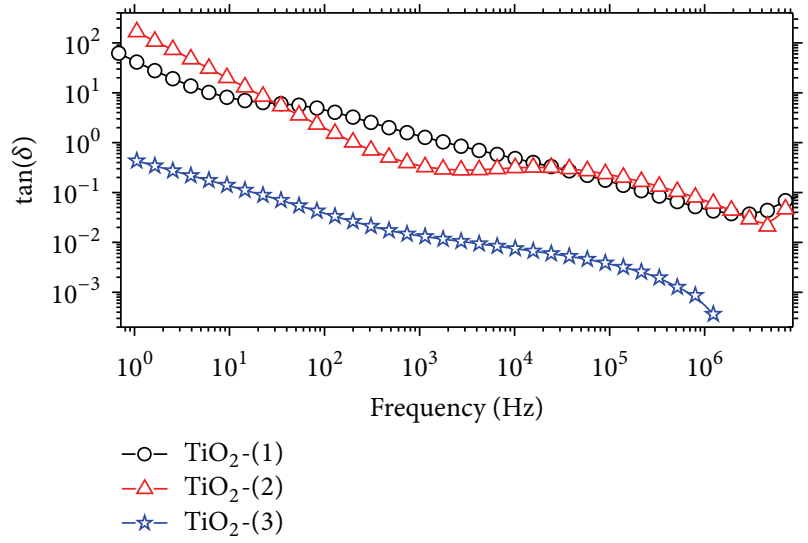

(b)

FIgURE 8: The frequency dependence of dielectric constant (a) and loss tangent (b) measured at $20^{\circ} \mathrm{C}$ for investigated rutile samples annealed for $2 \mathrm{~h}$ at $850^{\circ} \mathrm{C}$ (synthesis (1)) and at $900^{\circ} \mathrm{C}$ (syntheses (2) and (3)).

(1) exhibit the smallest sizes; thus this powder transforms to rutile particles at $850^{\circ} \mathrm{C}$ and possesses the highest value of dielectric permittivity. Samples $\mathrm{TiO}_{2}-(2)$ and $\mathrm{TiO}_{2}-(3)$ annealed at $900^{\circ} \mathrm{C}$ have similar size, as estimated by DLS, but they differ in dispersity index values. $\mathrm{TiO}_{2}-(1)$ and $\mathrm{TiO}_{2}-(3)$ have a similar PDI, whereas the $\mathrm{TiO}_{2}-(2)$ exhibits PDI equal to 0.715 meaning the broader variety in size of particles. This fact seems to be crucial in anatase-rutile transformation of $\mathrm{TiO}_{2}-(2)$ sample, which is a mixture of both crystallographic forms as evidenced by Raman studies in Figure 3, and exhibits the lowest value of dielectric permittivity. Specimen $\mathrm{TiO}_{2}$ (3) transformed to rutile phase after annealing at $850^{\circ} \mathrm{C}$ as shown in Figure 2. Because dielectric studies evidenced low values of dielectric constant, the sample was additionally annealed during two hours at $900^{\circ} \mathrm{C}$. The comparison of frequency representation for $\mathrm{TiO}_{2}-(3)$ annealed at $850^{\circ} \mathrm{C}$ and $900^{\circ} \mathrm{C}$ and measured at $20^{\circ} \mathrm{C}$ allowed observing an increase of $\varepsilon^{\prime}$ and the lowering of $\tan (\delta)$ values in the case of sample annealed at higher temperature (data presented in Table 1). With regard to Raman spectroscopy applied in our studies it is worth underlining that this technique is very useful for detecting transformation ratio in titania; however its sensitivity depends on used excitation line. In the case of core-shell structure of investigated powder, that is, anataserutile hybrid, it may give response either from outer or inner phase, thus leading to debated results and some inconsistency with dielectric results as evidenced in the case of $\mathrm{TiO}_{2}$ (3) sample annealed at $850^{\circ} \mathrm{C}$. $\mathrm{TiO}_{2}-(1)$ annealed at $850^{\circ} \mathrm{C}$ exhibits the highest value of dielectric permittivity but its dissipation factor is elevated and comparable to sample $\mathrm{TiO}_{2}$ (2) annealed at $900^{\circ} \mathrm{C}$ (see Figure 8). It results from the smallest size of $\mathrm{TiO}_{2}-(1)$ nanoparticles, which pressed to pellet form exhibits significant area of grains boundaries, that is, a source of dissipation energy in studied system.

The obtained dielectric permittivity values for investigated samples are slightly lower from previously found dielectric constants for powders of the anatase and rutile phases that have been reported to be equal to 48 [25] and
89 [26], respectively. It can be due to the known relationship between density of the sample and its dielectric properties, according to which higher density, that is, lower porosity, results in a higher dielectric permittivity that improves also quality factor value. The relative density of ceramic pellets studied by us was varying from 58 to $74 \%$. It means that measured materials were partially porous; thus they can be considered as capacitor composed of ceramic and air. Taking into account the relative density of $\mathrm{TiO}_{2}-(1)$ sample annealed at $850^{\circ} \mathrm{C}$ the recorded value of dielectric permittivity is in good agreement with above cited value for rutile form.

Figure 9 shows temperature dependence of dielectric constant and loss tangent measured at $1.15 \mathrm{MHz}$ for three rutile samples obtained from different syntheses and annealing procedure conducted: at $850^{\circ} \mathrm{C}$ for (1) product and at $900^{\circ} \mathrm{C}$ for (2) and (3) materials. It can be observed that dielectric constant follows the linear dependence in the range of temperature from $-140^{\circ} \mathrm{C}$ to $20^{\circ} \mathrm{C}$. From the range of the linearity, marked in Figure 9(a), the temperature coefficient $\left(\tau_{\varepsilon}\right)$ was calculated according to:

$$
\left.\tau_{\varepsilon}\right|_{-140^{\circ} \mathrm{C}} ^{20^{\circ} \mathrm{C}}=\frac{1}{\varepsilon_{\left(-140^{\circ} \mathrm{C}\right)}}\left(\frac{\Delta \varepsilon}{\Delta T}\right) \mathrm{ppm} /{ }^{\circ} \mathrm{C} .
$$

The temperature coefficient for $\mathrm{TiO}_{2}-(1)$ annealed at $850^{\circ} \mathrm{C}$ was calculated to be negative and equal $-579 \mathrm{ppm} /{ }^{\circ} \mathrm{C}$ that gives a comparable value found for titania $\left(\tau_{\varepsilon(\mathrm{TiO} 2)}<\right.$ $-500 \mathrm{ppm} /{ }^{\circ} \mathrm{C}$ ) [27]. The lower value of $\tau_{\varepsilon}$ was found for $\mathrm{TiO}_{2}-$ (3) annealed at $900^{\circ} \mathrm{C}\left(\tau_{\varepsilon}=-87\right)$. It is worth underlining that these two samples have a similar PDI index; however they differ in grain size. This fact seems to have significant influence both on temperature coefficient and on loss tangent values. The temperature coefficient value calculated for $\mathrm{TiO}_{2}-$ (2) annealed at $900^{\circ} \mathrm{C}$ was not taken into account in above comparison, because this rutile sample is contaminated by anatase form. The electric parameters of all investigated samples are gathered in Table 1 . 


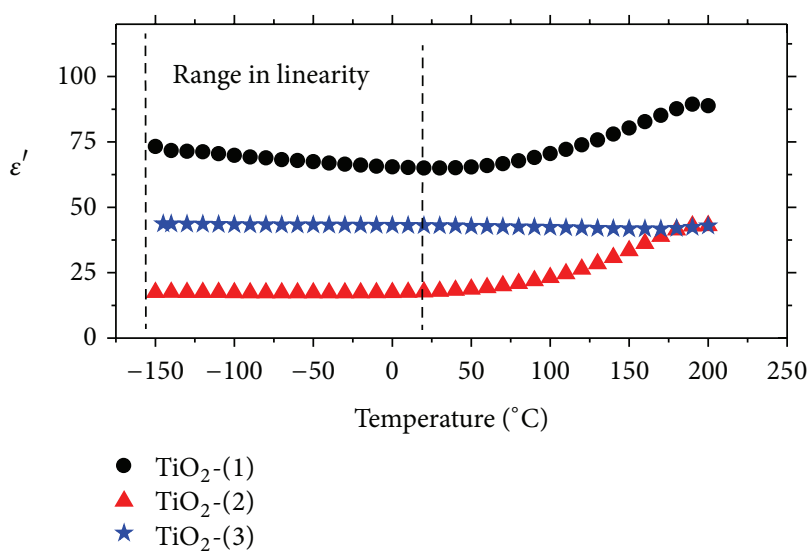

(a)

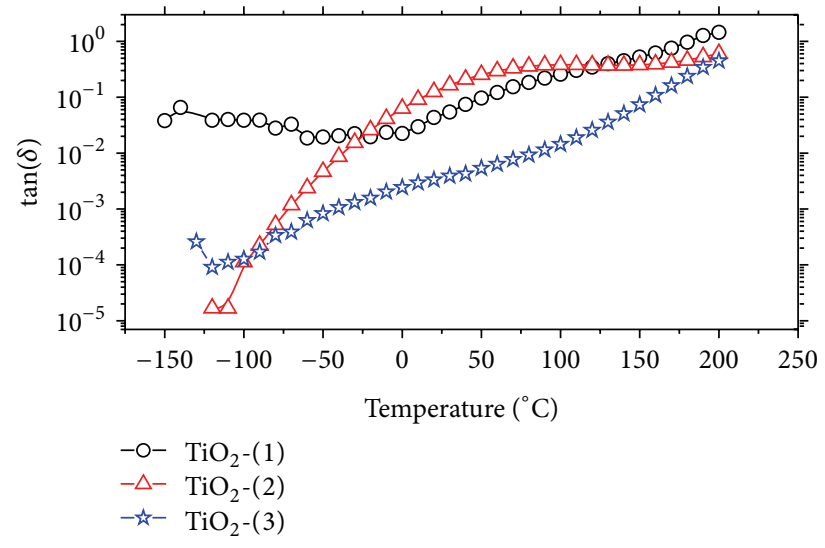

(b)

FIGURE 9: The temperature dependence of (a) dielectric constant and (b) loss tangent measured at $1.15 \mathrm{MHz}$ for investigated rutile samples annealed for $2 \mathrm{~h}$ at $850^{\circ} \mathrm{C}$ (synthesis (1)) and at $900^{\circ} \mathrm{C}$ (syntheses (2) and (3)).

TABLE 1: Relative densities and dielectric properties of the $\mathrm{TiO}_{2}$ pellets measured at $1.15 \mathrm{MHz}$ and at temperature of $20^{\circ} \mathrm{C}$. The titania pellets were additionally annealed for 2 hours at the same temperature as the temperature applied during annealing of powder.

\begin{tabular}{lccccc}
\hline Synthesis & $\begin{array}{c}\text { Annealing temperature } \\
\text { of } \mathrm{TiO}_{2} \text { powder } \\
{\left[{ }^{\circ} \mathrm{C}\right]}\end{array}$ & $\begin{array}{c}\text { Relative } \\
\text { density }[\%]\end{array}$ & $\begin{array}{c}\text { Dielectric } \\
\text { constant }(\varepsilon)\end{array}$ & $\begin{array}{c}\tan (\delta) \\
\text { Temperature coefficient } \\
{\left[\mathrm{ppm} /{ }^{\circ} \mathrm{C}\right]}\end{array}$ \\
\hline$(1)$ & $600_{\text {(anatase) }}$ & 61 & 18.9 & 0.130 & - \\
$(1)$ & $850_{\text {(rutile) }}$ & 74 & 63.7 & 0.051 & -579 \\
$(2)$ & $900_{\text {(anatase-rutile) }}$ & 58 & 17.0 & 0.055 & $-68^{*}$ \\
$(3)$ & $850_{\text {(rutile) }}$ & 59 & 23.0 & 0.032 & - \\
$(3)$ & $900_{\text {(rutile) }}$ & 66 & 43.2 & $4 \cdot 10^{-4}$ & -87 \\
\hline
\end{tabular}

${ }^{*}$ Value calculated in a temperature range from $-140^{\circ} \mathrm{C}$ to $-10^{\circ} \mathrm{C}$.

\section{Conclusion}

According to the Raman spectra, the anatase-rutile phase transformation of sample synthesised via sol-gel method is initiated at about $750^{\circ} \mathrm{C}$, whereas the anatase phase completely transforms to the rutile phase when the sample is annealed at temperature up to $850^{\circ} \mathrm{C}$. The transformation of $\mathrm{TiO}_{2}$ synthesised via precipitation method is completed between 850 and $900^{\circ} \mathrm{C}$, whereas the transformation of $\mathrm{TiO}_{2}$ synthesised via hybrid layered tetramethyl (ammonium) titanate precursor is not completed up to $900^{\circ} \mathrm{C}$. The comparison of Raman results with analysis of samples microstructure (DLS and SEM) reveals that the lowest temperature of complete transformation is observed for the sample containing the smallest grains, that is, $\mathrm{TiO}_{2}-(1)$. Titania obtained from syntheses (2) and (3) and annealed at $900^{\circ} \mathrm{C}$ shows similar mean size of particles; however the transformation of sample $\mathrm{TiO}_{2}$-(2) was not completed. The $\mathrm{TiO}_{2}$-(2) sample characterised by the highest dispersity index has the highest temperature of transformation. The obtained results seem to indicate the relation between the anatase-rutile structural transformation and size and dispersity of grains subjected to annealing. The rutile nanoparticles obtained via sol-gel method and annealed at $850^{\circ} \mathrm{C}$ exhibit the lowest size of grains and the lowest PDI value that can be associated with the highest value of dielectric permittivity obtained for this sample. The dielectric constant measured at room temperature is equal to 63.7, whereas its dielectric temperature coefficient equals $-579 \mathrm{ppm} /{ }^{\circ} \mathrm{C}$ and presents characteristic negative tendency. For samples $\mathrm{TiO}_{2}-(3)$ annealed at $900^{\circ} \mathrm{C}$ the lowest loss tangent and temperature coefficient values were detected that probably results from uniform grain structure and smaller area of grain boundary than in the case of $\mathrm{TiO}_{2}-(1)$ annealed at $850^{\circ} \mathrm{C}$. It was found that dielectric parameters strictly depended on a rate of anatase-rutile transformation, morphology of investigated powders, and relative density of measured pellets.

\section{Conflict of Interests}

The authors declare that there is no conflict of interests regarding the publication of this paper.

\section{Acknowledgments}

This work was financially supported by the National Science Center (Poland) grant awarded by Decision no. DEC2011/03/D/ST5/06074. The authors are grateful to Professor Adam Tracz from the Polish Academy of Science in Lodz for his help in performing SEM investigations. 


\section{References}

[1] H. Zhang and J. F. Banfield, "Kinetics of crystallization and crystal growth of nanocrystalline anatase in nanometer-sized amorphous titania," Chemistry of Materials, vol. 14, no. 10, pp. 4145-4154, 2002.

[2] R. J. Tayade, P. K. Surolia, R. G. Kulkarni, and R. V. Jasra, "Photocatalytic degradation of dyes and organic contaminants in water using nanocrystalline anatase and rutile $\mathrm{TiO}_{2}$," Science and Technology of Advanced Materials, vol. 8, no. 6, pp. 455-462, 2007.

[3] B. A. Al-Asbahi, M. H. H. Jumali, C. C. Yap, and M. M. Salleh, "Influence of $\mathrm{TiO}_{2}$ nanoparticles on enhancement of optoelectronic properties of PFO-based light emitting diode," Journal of Nanomaterials, vol. 2013, Article ID 561534, 7 pages, 2013.

[4] L.-X. Pang, H. Wang, D. Zhou, and X. Yao, "Low-temperature sintering and microwave dielectric properties of $\mathrm{TiO}_{2}$-based LTCC materials," Journal of Materials Science, vol. 21, no. 12, pp. 1285-1292, 2010.

[5] M. Crippa, A. Bianchi, D. Cristofori et al., "High dielectric constant rutile-polystyrene composite with enhanced percolative threshold," Journal of Materials Chemistry C, vol. 1, pp. 484-492, 2013.

[6] X. Huang, Z. Pu, L. Tong, Z. Wang, and X. Liu, "Preparation and dielectric properties of surface modified $\mathrm{TiO}_{2} / \mathrm{PEN}$ composite films with high thermal stability and flexibility," Journal of Materials Science, vol. 23, pp. 2089-2097, 2012.

[7] R. P. Ortiz, A. Facchetti, and T. J. Marks, "High-k organic, inorganic, and hybrid dielectrics for low-voltage organic fieldeffect transistors," Chemical Reviews, vol. 110, no. 1, pp. 205-239, 2010.

[8] J. Shi and X. Wang, "Growth of rutile titanium dioxide nanowires by pulsed chemical vapor deposition," Crystal Growth and Design, vol. 11, no. 4, pp. 949-954, 2011.

[9] C. J. Tavares, S. M. Marques, L. Rebouta et al., "PVD-Grown photocatalytic $\mathrm{TiO}_{2}$ thin films on PVDF substrates for sensors and actuators applications," Thin Solid Films, vol. 517, no. 3, pp. 1161-1166, 2008.

[10] X. Chen and S. S. Mao, "Titanium dioxide nanomaterials: synthesis, properties, modifications and applications," Chemical Reviews, vol. 107, no. 7, pp. 2891-2959, 2007.

[11] H. Yin, Y. Wada, T. Kitamura et al., "Hydrothermal synthesis of nanosized anatase and ruffle $\mathrm{TiO}_{2}$ using amorphous phase $\mathrm{TiO}_{2}$," Journal of Materials Chemistry, vol. 11, no. 6, pp. 16941703, 2001.

[12] A. di Paola, M. Bellardita, R. Ceccato, L. Palmisano, and F. Parrino, "Highly active photocatalytic $\mathrm{TiO}_{2}$ powders obtained by thermohydrolysis of $\mathrm{TiCl}_{4}$ in water," Journal of Physical Chemistry C, vol. 113, no. 34, pp. 15166-15174, 2009.

[13] S. Cassaignon, M. Koelsch, and J.-P. Jolivet, "Selective synthesis of brookite, anatase and rutile nanoparticles: thermolysis of $\mathrm{TiCl}_{4}$ in aqueous nitric acid," Journal of Materials Science, vol. 42, no. 16, pp. 6689-6695, 2007.

[14] M. A. Behnajady, H. Eskandarloo, N. Modirshahla, and M. Shokri, "Sol-gel low-temperature synthesis of stable anatasetype $\mathrm{TiO}_{2}$ nanoparticles under different conditions and its photocatalytic activity," Photochemistry and Photobiology, vol. 87, no. 5, pp. 1002-1008, 2011.

[15] T. Ohya, A. Nakayama, T. Ban, Y. Ohya, and Y. Takahashi, "Synthesis and characterization of halogen-free, transparent, aqueous colloidal titanate solutions from titanium alkoxide," Chemistry of Materials, vol. 14, no. 7, pp. 3082-3089, 2002.

[16] W. Li and T. Zeng, "Preparation of $\mathrm{TiO}_{2}$ anatase nanocrystals by $\mathrm{TiCl}_{4}$ hydrolysis with additive $\mathrm{H}_{2} \mathrm{SO}_{4}$, $P L O S O N E$, vol. 6 , no. 6, Article ID e21082, 2011.

[17] J. Zhang, M. Li, Z. Feng, J. Chen, and C. Li, "UV raman spectroscopic study on $\mathrm{TiO} 2-\mathrm{I}$. Phase transformation at the surface and in the bulk," Journal of Physical Chemistry B, vol. 110, no. 2, pp. 927-935, 2006.

[18] S. Marinel, D. H. Choi, R. Heuguet, D. Agrawal, and M. Lanagan, "Broadband dielectric characterization of $\mathrm{TiO}_{2}$ ceramics sintered through microwave and conventional processes," Ceramics International, vol. 39, pp. 299-306, 2013.

[19] Y. Zhang, C. X. Harris, P. Wallenmeyer, J. Murowchick, and $\mathrm{X}$. Chen, "Asymmetric lattice vibrational Characteristics of Rutile $\mathrm{TiO}_{2}$ as revealed by laser power dependent raman spectroscopy," Journal of Physical Chemistry C, vol. 117, pp. 24015-24022, 2013.

[20] I. E. Campbell and E. M. Sherwood, Eds., High-Temperature Materials and Technology, Wiley, New York, NY, USA, 1967.

[21] J. Zhang, Q. Xu, M. Li, Z. Feng, and C. Li, "UV Raman spectroscopic study on $\mathrm{TiO}_{2}$-II. Effect of nanoparticle size on the outer/inner phase transformations," Journal of Physical Chemistry C, vol. 113, no. 5, pp. 1698-1704, 2009.

[22] D. H. Wang, W. C. Goh, M. Ning, and C. K. Ong, "Effect of $\mathrm{Ba}$ doping on magnetic, ferroelectric, and magnetoelectric properties in mutiferroic $\mathrm{BiFe}_{3}$ at room temperature," Applied Physics Letters, vol. 88, no. 21, Article ID 212907, 2006.

[23] J. J. Mohamed, S. D. Hutagalung, M. F. Ain, and Z. A. Ahmad, "Effect of excess $\mathrm{TiO}_{2}$ in $\mathrm{CaCu}_{3} \mathrm{Ti}_{4} \mathrm{O}_{12}$ on the microstructure and dielectric properties," Journal of Ceramic Processing Research, vol. 12, no. 5, pp. 496-499, 2011.

[24] M. C. Romeu, R. G. M. Oliveira, and A. J. M. Sales, "Impedance spectroscopy study of $\mathrm{TiO}_{2}$ addition on the ceramic matrix $\mathrm{Na}_{2} \mathrm{Nb}_{4} \mathrm{O}_{11}$," Journal of Materials Science-Materials in Electronics, vol. 24, pp. 4993-4999, 2013.

[25] L. A. Harris, "Titanium dioxide hydrogen detector," Journal of the Electrochemical Society, vol. 127, no. 12, pp. 2657-2662, 1980.

[26] F. A. Grant, "Properties of rutile (titanium dioxide)," Reviews of Modern Physics, vol. 31, no. 3, pp. 646-674, 1959.

[27] K. Haga, T. Ishii, J.-I. Mashiyama, and T. Ikeda, "Dielectric properties of two-phase mixture ceramics composed of rutile and its compounds," Japanese Journal of Applied Physics, vol. 31, no. 9, pp. 3156-3159, 1992. 

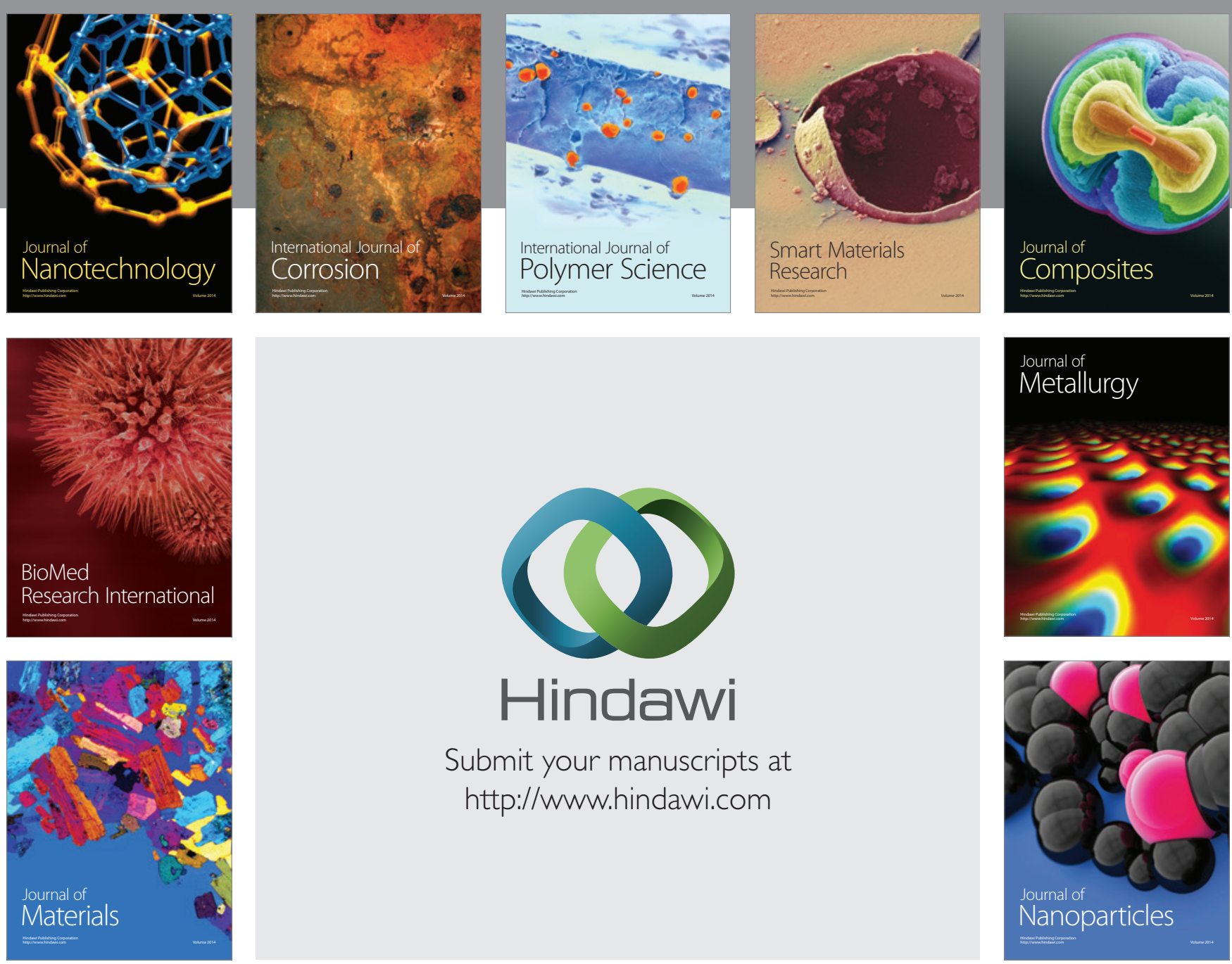

Submit your manuscripts at http://www.hindawi.com
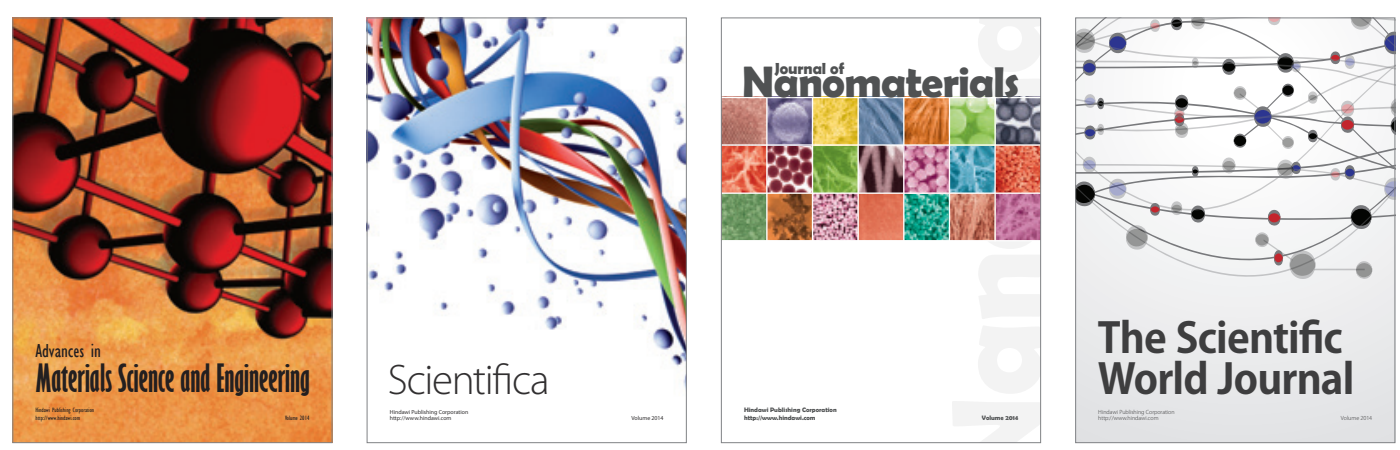

\section{The Scientific World Journal}
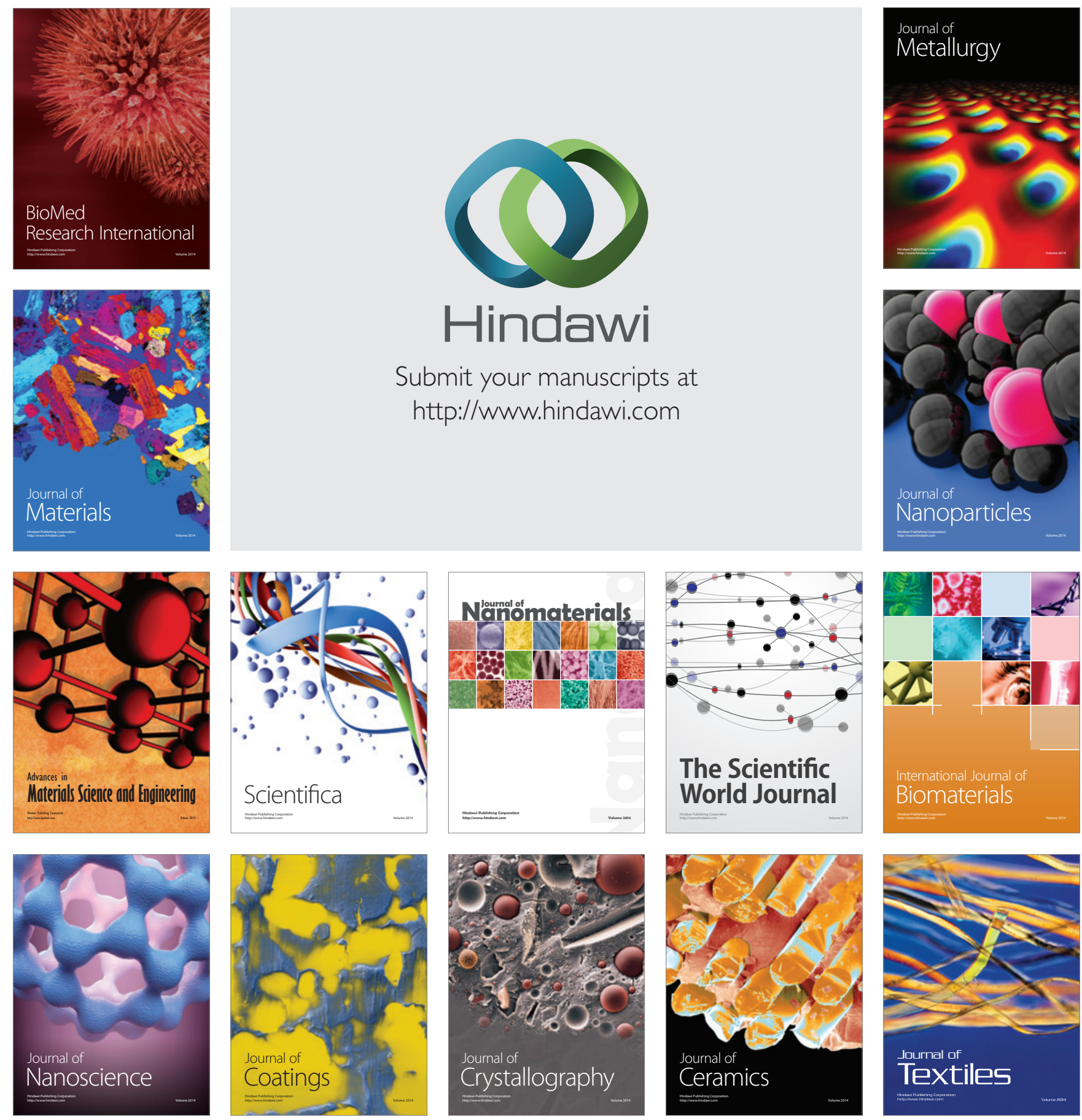